\title{
Optical and Dispersion parameters of ZnS Thin Films Prepared by Flash Evaporation Method
}

\author{
Nabeel A. Bakr ${ }^{1}$, Nidhal N. Jandow ${ }^{2}$, Nadir F. Habubi ${ }^{2, *}$ \\ ${ }^{1}$ Department of Physics, College of Science, University of Diyala, Diyala, Iraq \\ ${ }^{2}$ Department of Physics, College of Education, Al-Mustansiriyah University, Baghdad, Iraq \\ *E-mail address: nadirfadhil@yahoo.com
}

\begin{abstract}
Zns thin films are obtained by flash evaporation method onto preheated glass substrates. The transmittance analysis allowed the determination of refractive index and thickness using envelope method. It was found that the refractive dispersion data obeyed the single oscillator model. The calculated value of the refractive index $\left(\mathrm{n}_{\mathrm{o}}\right)$ was found to be equal to 2.27 , which is in a good agreement with the value obtained from Cauchy's fitting. Also the value of the optical energy gap, extinction coefficient, real and imaginary parts of the dielectric constant and optical conductivity have been measured.
\end{abstract}

Keywords: ZnS thin film; flash evaporation; Swanepoel technique; single oscillator model

\section{INTRODUCTION}

Recently there has been a considerable attention on Zinc sulphide (ZnS) due to its wide applications. $\mathrm{ZnS}$ with a wide optical gap $(\sim 3.7 \mathrm{eV})$ has unique physical properties, such as high refractive index (2.3), low optical absorption in the visible and infrared spectral region $(0.4-13 \mu \mathrm{m})$ and high effective dielectric constant (9) [1,2]. The use of a wider band gap S.C., such as $\mathrm{ZnS}$ instead of $\mathrm{CdS}$ could cause to decrease in window absorption losses and improve the short circuit current $[3,4]$.

There has been a considerable progress to use $\mathrm{ZnS}$ in CIGS thin film solar cells with efficiency up to $18.6 \%$ [5]. It can be used as a light emitting diode (LED) in blue to ultraviolet spectrum region [6]. $\mathrm{ZnS}$ is a promising material that can be used as a beam splitting and a band pass filter over the region between 400 and $1400 \mathrm{~nm}$ [7], also, it can be used in the future of data storage and data transfer. $\mathrm{ZnS}$ has a low excitonic Bohr radius of $(2.5 \mathrm{~nm})$ that makes its nanoparticle interesting as small biomoleculer probes for laser scanning microscope [8].

Various techniques have been used to prepare $\mathrm{ZnS}$ such as close-spaced vacuum sublimation technique (CSVS) [9], pulse plated [10], thermal evaporation [11], successive ionic layer adsorption and reaction (SILAR) [12], RF magnetron sputtering [13], chemical vapor deposition [14], electrodeposition [15], spray pyrolysis [16], and flash evaporation technique [17].

In this work, we report the preparation of $\mathrm{ZnS}$ thin films on glass substrates by using flash evaporation method and subsequently the optical properties of $\mathrm{ZnS}$ thin films were 
characterized by a transmission spectrum to utilize Swanepoel method and Wemple Didomenico model for dispersion relation, etc. [32-37].

\section{EXPERIMENTAL PROCEDURE}

$\mathrm{ZnS}$ thin films were prepared by the flash evaporation method on a preheated glass substrate at $100{ }^{\circ} \mathrm{C}$ in order to get uniform films which was clearly seen in the transmittance spectra. High purity of $\mathrm{ZnS}$ (from the Sigma - Aldirch company) were evaporated by using a molybdenum boat filament in a high vacuum chamber evacuated to $\sim 10^{-6}$ Torr. During the deposition, the filament and the substrate were kept about $10 \mathrm{~cm}$ apart from the target. According to this distance the resultant films were quite uniform. The thickness of the deposited films was measured by Gravimetric method and was compared with the thickness obtained from the envelope method. Optical transmittance spectra were recorded by a double beam UV/Vis spectrophotometer (Shimdzu-1650 U-probe, Japan) in the wavelength range (340-900 nm).

\section{RESULTS AND DISCUSSION}

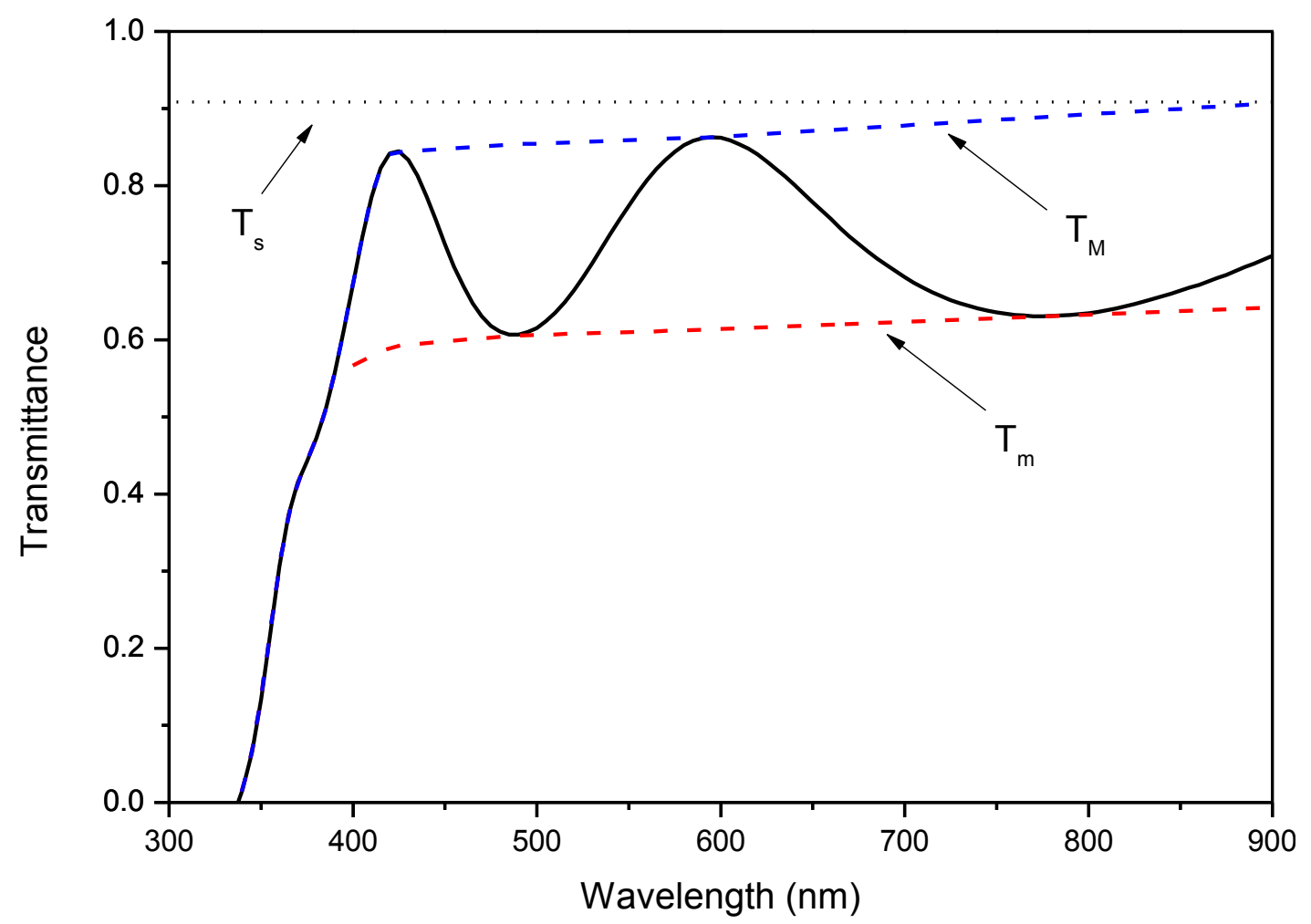

Fig. 1. The optical transmission spectrum of $\mathrm{ZnS}$ film vs. wavelength.

Figure 1 represents the optical transmission spectrum of $\mathrm{ZnS}$ film of $300 \mathrm{~nm}$ thickness measured by Gravimetric method. The interference maxima and minima due to multiple reflection on film surface can be observed. According to Swanepoel [18], the transmission T for normal incidence is given by $[19,20]$ : 


$$
T=\frac{A x}{B-C x \cos \phi+D x^{2}}
$$

where $A=16 n^{2} n_{s}, B=(n+1)^{3}\left(n+n_{s}\right)^{2}, \phi=4 \pi n d$, and $x=\exp (-\alpha d)$

The interference fringes can be obtained from Eq.1 by setting the interference condition $\cos \varphi=1$ and $\cos \varphi=1$ for $T$ maxima $\left(T_{M}(\lambda)\right)$ and $T$ minima $\left(T_{m}(\lambda)\right)$ respectively.

The refractive index (n) of the film with uniform thickness can be calculated from the two envelopes, $\left(T_{M}(\lambda)\right)$ and $\left(T_{m}(\lambda)\right)$, by considering the extremes of the interference fringes,

Maxima

$$
T_{M}=\frac{A x}{B-C x+D x^{2}}
$$

Minima

$$
T_{m}=\frac{A x}{B+C x+D x^{2}}
$$

Subtracting the reciprocals of Eq. 2 into Eq. 3 yields an expression that is independent of the absorbance, $\mathrm{x}$ :

$$
\frac{1}{T_{m}}-\frac{1}{T_{M}}=\frac{2 C}{A}
$$

Rearranging it for $\mathrm{n}$, one can get the expression:

$$
n=\left[N_{1}+\left(N_{1}^{2}-s^{2}\right)^{1 / 2}\right]^{1 / 2}
$$

where

$$
N_{1}=2 s \frac{T_{M}-T_{m}}{T_{M} \times T_{m}}+\frac{s^{2}+1}{2}
$$

$T_{M}$ and $T_{m}$ are the two envelopes constructed from the measured transmission spectrum using a suitable computer program to cover the original transmission spectrum, and $n_{s}$ is the refractive index of the substrate. Since the last equation is not valid in the strong absorption region, where there are no maxima and minima, the calculated refractive index was fitted to a dispersion model, such as two-term Cauchy dispersion relationship, for extrapolation to shorter wavelengths before it can be used to obtain other optical constants. The substrate refractive index $\left(\mathrm{n}_{\mathrm{s}}\right)$ can be easily calculated by measuring the transmittance of the substrate alone $\left(\mathrm{T}_{\mathrm{s}}\right)$ using the well known equation:

$$
s=\frac{1}{T_{s}}+\left(\frac{1}{T_{s}}-1\right)^{1 / 2}
$$

The values of $T_{M}$ and $T_{m}$ shown in table (1) are the transmission maximum and the corresponding minimum at a certain wavelength $(\lambda)$, one being measured and the other calculated from the envelopes. The refractive index values can be obtained from (Eq. 5) are 
shown as $\mathrm{n}_{1}$ for demonstration in the Table 1 and these values will be improved after calculating film thickness (d) as will be explained below.

If $n_{\mathrm{e} 1}$ and $\mathrm{n}_{\mathrm{e} 2}$ are the refractive indices of two adjacent maxima and minima at $\lambda_{1}$ and $\lambda_{2}$ then, the film thickness is given by the expression:

$$
d=\frac{\lambda_{1} \lambda_{2}}{2\left(\lambda_{1} n_{e 2}-\lambda_{2} n_{e 1}\right)}
$$

The values of the determined (d) using this equation are listed in Table 1 . The average value of $\mathrm{d}_{1}\left(\overline{d_{1}}\right)$ can be used now along with the values of $\lambda$ and $\mathrm{n}_{1}$ to estimate the values of interference order $\left(\mathrm{m}_{\mathrm{o}}\right)$ using the equation below:

$$
2 n d=m \lambda \text {. }
$$

The values of $\mathrm{m}_{\mathrm{o}}$ must be corrected to the exact integers or half integers. These corrected values $(m)$ can be used to calculate new values of thickness $\left(d_{2}\right)$. The average thickness $\left(\overline{d_{2}}\right)$ can be used now along with the values of $\lambda$ and $m$ to calculate the improved values of $n$ which are shown in the Table $1 a n_{2}$. Now the values of $n_{2}$ can be fitted to twoterm Cauchy dispersion relationship [21].

$$
n=a+\frac{b}{\lambda^{2}}
$$

where a and be are coefficients that can be determined for a material by fitting the equation to measure refractive indices at known wavelengths. This can be used for extrapolation to short wavelengths. It is clear that the calculated thickness using the envelope method is in good agreement with the thickness value which is measured by gravimetric method and the difference is $\sim 4 \%$.

Table 1. A summary of the values of $T_{M}, T_{m}, s, n_{1}, d_{1}, m_{0}, m, d_{2}, n_{2}$ for $\mathrm{ZnS}$ thin film the underlined

\begin{tabular}{|c|c|c|c|c|c|c|c|c|c|}
\hline$\lambda(\mathrm{nm})$ & $\mathrm{T}_{\mathrm{M}}$ & $\mathrm{T}_{\mathrm{m}}$ & $\mathrm{S}$ & $\mathrm{n}_{1}$ & $\begin{array}{c}\mathrm{d}_{1} \\
(\mathrm{~nm})\end{array}$ & $\mathrm{m}_{\mathrm{o}}$ & $\mathrm{m}$ & $\begin{array}{c}\mathrm{d}_{2} \\
(\mathrm{~nm})\end{array}$ & $\mathrm{n}_{2}$ \\
\hline 775.0 & $\underline{0.889}$ & 0.631 & 1.533 & 2.402 & ....... & 2.333 & 1.790 & 1.500 & 242.0 \\
\hline 595.0 & 0.863 & 0.614 & 1.533 & 2.416 & ... & 2.350 & 2.000 & 246.3 & 2.388 \\
\hline 486.8 & 0.854 & 0.606 & 1.533 & 2.428 & 264.9 & 2.890 & 2.500 & 250.6 & 2.442 \\
\hline \multirow[t]{3}{*}{422.5} & 0.844 & $\underline{0.593}$ & 1.533 & 2.458 & 314.9 & 3.370 & 3.000 & 257.9 & 2.543 \\
\hline & & & & & \multirow[b]{2}{*}{$\begin{array}{l}(\overline{d 1})= \\
289.9\end{array}$} & & & \multirow{2}{*}{$\begin{array}{c}\left(\overline{d_{2}}\right) \\
= \\
249.2\end{array}$} & \\
\hline & & & & & & & & & \\
\hline
\end{tabular}
and bold values are calculated from the envelopes. The values of refractive index and film thickness are calculated according to the envelope method. 


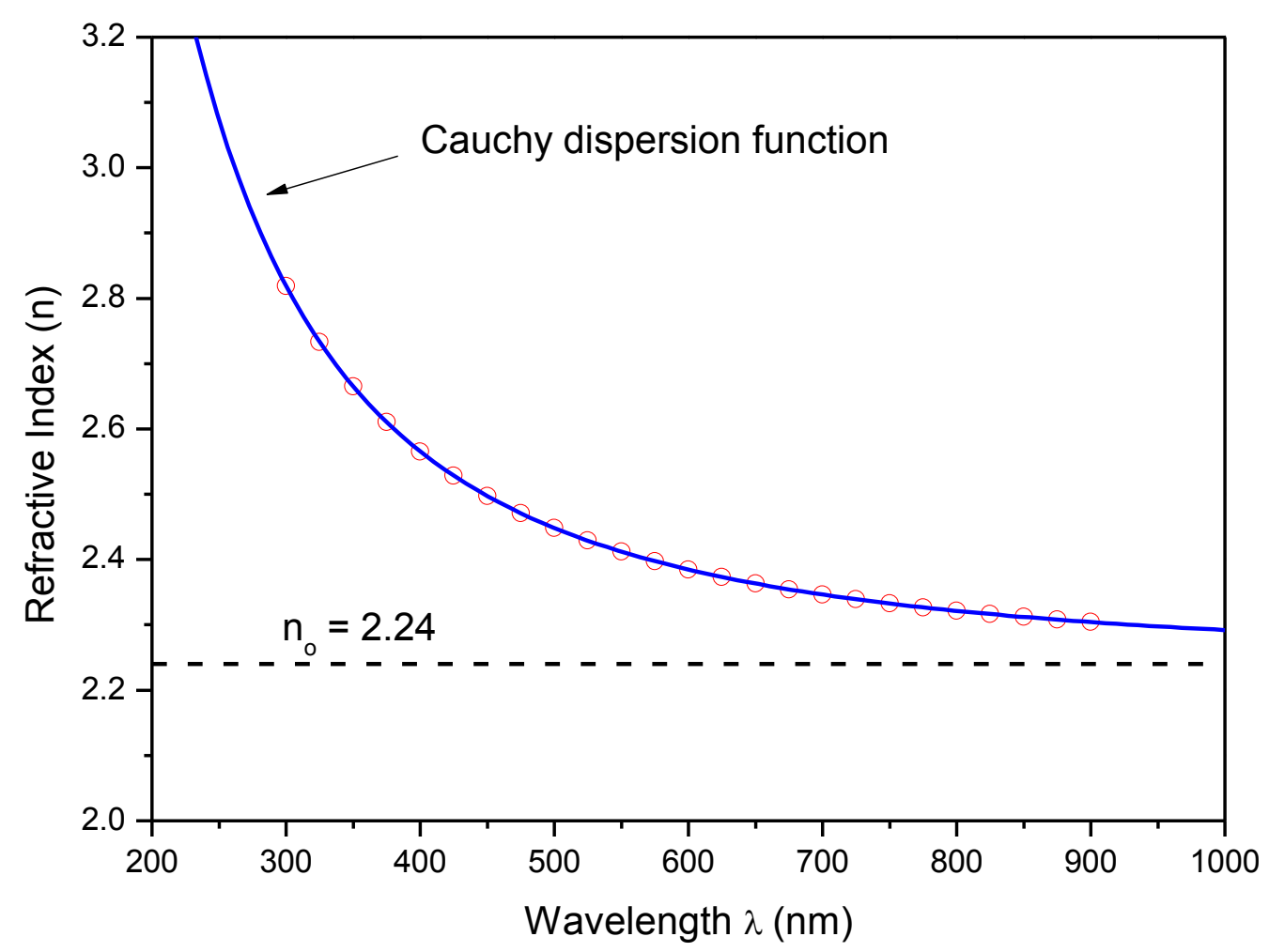

Fig. 2. the variation of refractive index obtained from the Cauchy relation vs. wavelength.

According to the single- effective oscillator model proposed by Wemple and DiDomenico $[22,23]$ the optical data can be described to an excellent approximation by the relation:

$$
n^{2}-1=\frac{E_{d} E_{o}}{E_{o}^{2}-E^{2}}
$$

where $(E=h v)$ is the photon energy, $n$ is the refractive index, $E_{o}$ is the single- effective oscillator energy and $E_{d}$ is the dispersion energy which is a measure of the average strength of the inter-band optical transitions. Plotting $\left(n^{2}-1\right)^{-1}$ against $E^{2}$ gives the oscillator parameters by fitting a straight line. Figure 3 shows the Plot of $\left(n^{2}-1\right)^{-1}$ versus $E^{2}$ for $\mathrm{ZnS}$ sample. The values of $E_{o}$ and $E_{d}$ can be then calculated from the slope $\left(E_{0} E_{d}\right)^{-1}$ which is the intercept on the vertical axis $\left(E_{o} / E_{d}\right)$. The calculated values of $E_{o}$ and $E_{d}$ were found to be $6.256 \mathrm{eV}$ and 25.99 $\mathrm{eV}$ respectively.

Furthermore, the values of the static refractive index $\left(n_{0}\right)$ can be calculated by extrapolating the Wemple-DiDomenic dispersion equation to $E_{0}$. The calculated value of $n_{0}$ was found equal to 2.27 and this value is in a good agreement with the obtained value from Cauchy fitting (see Fig. 2).In addition, the optical band gap $\left(\mathrm{E}_{\mathrm{g}}\right)$ can be also determined from the Wemple-DiDomenic dispersion parameter $E_{0}$, which can be related in a close approximation $\mathrm{E}_{\mathrm{o}} \approx 2 \mathrm{E}_{\mathrm{g}}[23]$. 


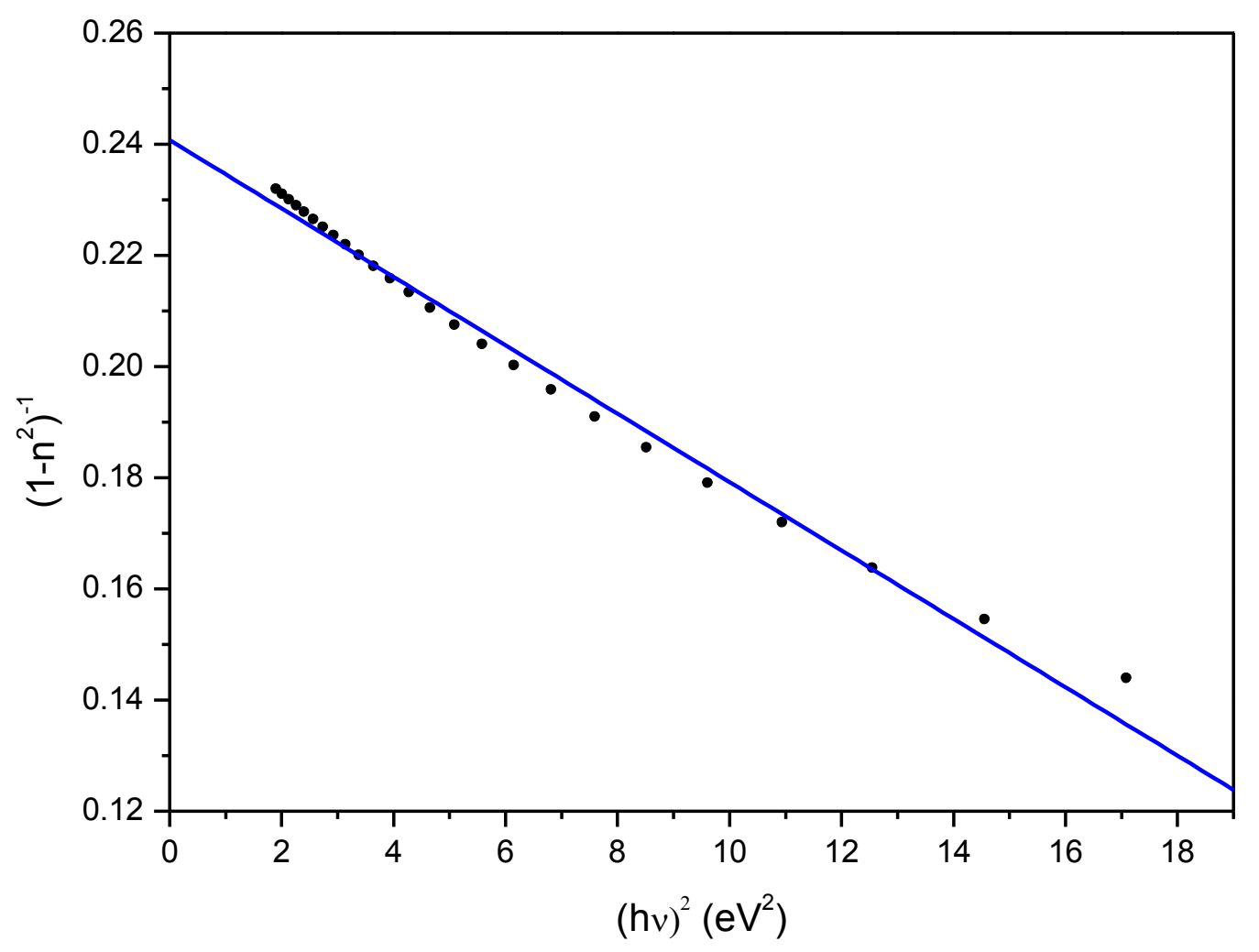

Fig. 3. $\left(1-n^{2}\right)^{-1}$ versus $(h v)^{2}$ for $\mathrm{ZnS}$ thin film.

The absorption coefficient $(\alpha)$ can be calculated using the equation [24]:

$$
\alpha=\frac{1}{d} \times \ln (x)
$$

where $\mathrm{d}$ is the film thickness and $\mathrm{x}$ is the absorbance which is given by the well known formula [25]:

$$
x=\frac{p+\left[p^{2}+2 Q T_{\alpha}\left(1-R_{2} R_{3}\right)^{1 / 2}\right.}{Q}
$$

where

$$
P=\left(R_{1}-1\right)\left(R_{2}-1\right)\left(R_{3}-1\right)
$$

and

$$
Q=2 T_{\alpha}\left(R_{1} R_{2}+R_{1} R_{3}-2 R_{1} R_{2} R_{3}\right)
$$

$\mathrm{R}_{1}, \mathrm{R}_{2}$, and $\mathrm{R}_{3}$ are the reflectance of the air-film, film-substrate and substrate-air interfaces respectively and are given by:

$$
R_{1}=\left[\frac{1-n}{1+n}\right]^{2}, R_{2}=\left[\frac{n-s}{n+s}\right]^{2} \text { and } R_{3}=\left[\frac{s-1}{s+1}\right]^{2}
$$


In the spectral region with the interference the interference fringes, Ta is the geometric mean of TM and Tm and is given by:

$$
T_{\alpha}=\left(T_{M} \times T_{m}\right)^{1 / 2}
$$

Following Tauc's model [26] in the direct transition $\mathrm{ZnS}$ semiconductor, the absorption coefficient is related to the optical band gap for high photon energy as:

$$
(\alpha h v)^{2}=A\left(h v-E_{g}\right)
$$

where $\mathrm{A}$ is constant and hv is the energy of the incident photon.

The band gap $\left(\mathrm{E}_{\mathrm{g}}\right)$ is determined by extrapolating the linear part of $(\alpha \mathrm{hv})^{2}$ to word the hv axis leading to an estimated value of $3.61 \mathrm{eV}$ as shown in Fig. (4) and this value is in a good agreement with the obtained value by Roy et al. [27], T. Keuchi et al. [28] and Doña and Herrero [29].

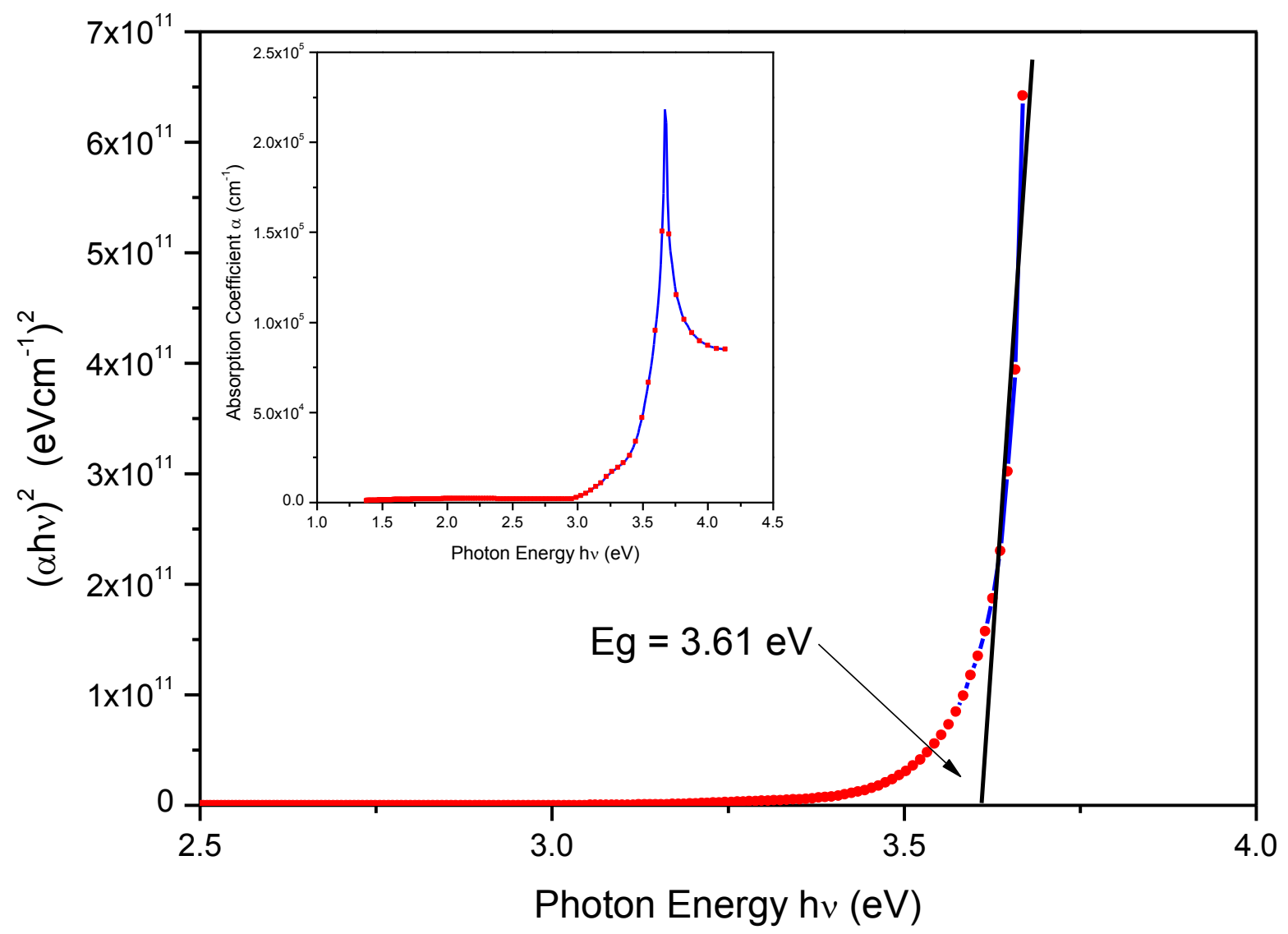

Fig. 4. Band gap derivation by Tauc Model for $\mathrm{ZnS}$ thin film.

The imaginary part of the complex index of refraction $\mathrm{k}$ is a measure of the fraction of light lost due to scattering and absorption per unit distance of the penetration medium. It can be estimated from the values of $\alpha$ and $\lambda$ using the relation [30]: From Fig. 5, it can be seen that the extinction coefficient decreases as the wavelength increases. 


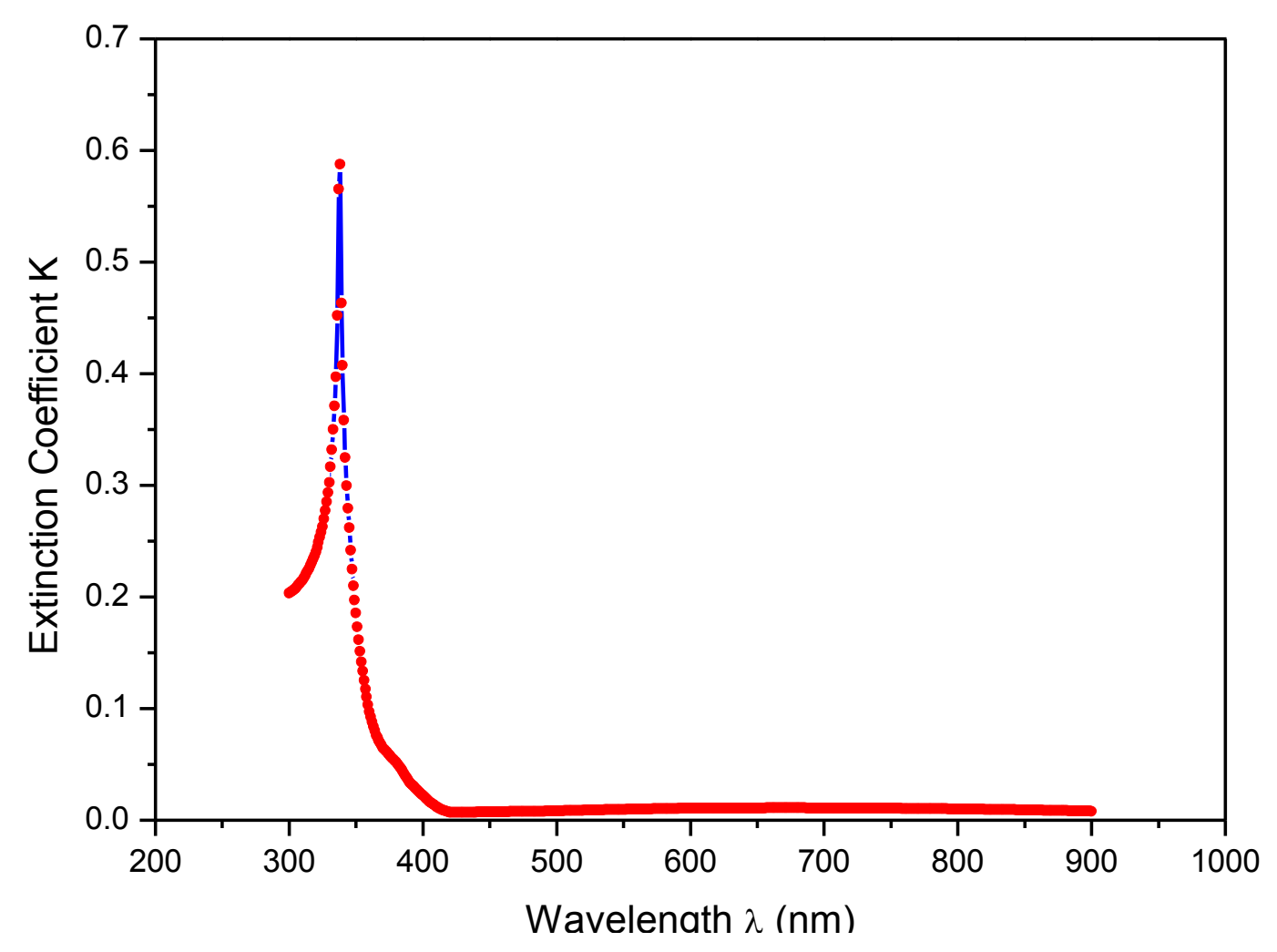

Fig. 5. The variation of extinction coefficient of $\mathrm{ZnS}$ thin film on wavelength.

$$
\varepsilon_{r}=n^{2}-k^{2} \quad \text { and } \quad \varepsilon_{i}=2 n k
$$

where the real part describes the propagation characteristics, while the imaginary part describes the rate of attenuation along the propagation direction. Figures 6 and 7 present the dependence of the dielectric constant of $\mathrm{ZnS}$ thin film. The values of the real part are higher than those of the imaginary part, Fig. 6 also shows that the real decreases exponentially as the wavelength increases while Fig. 7 shows that the imaginary part also decrease as the wavelength increases in the range of 300 to $420 \mathrm{~nm}$ and then keep with a constant value in the range above 420 to $900 \mathrm{~nm}$. The optical response of the $\mathrm{ZnS}$ is mainly studied in terms of the optical conductivity $(\sigma)$ which is given by the relation [24]:

$$
\sigma=\frac{\alpha n c}{4 \pi}
$$

Figure 8 shows the dependence of the optical conductivity on the wavelength, from the figure we can see that the optical conductivity decreases with the increasing of wavelength which could be related to the decrease in the extinction coefficient and the density of localized states in the gap [31]. 


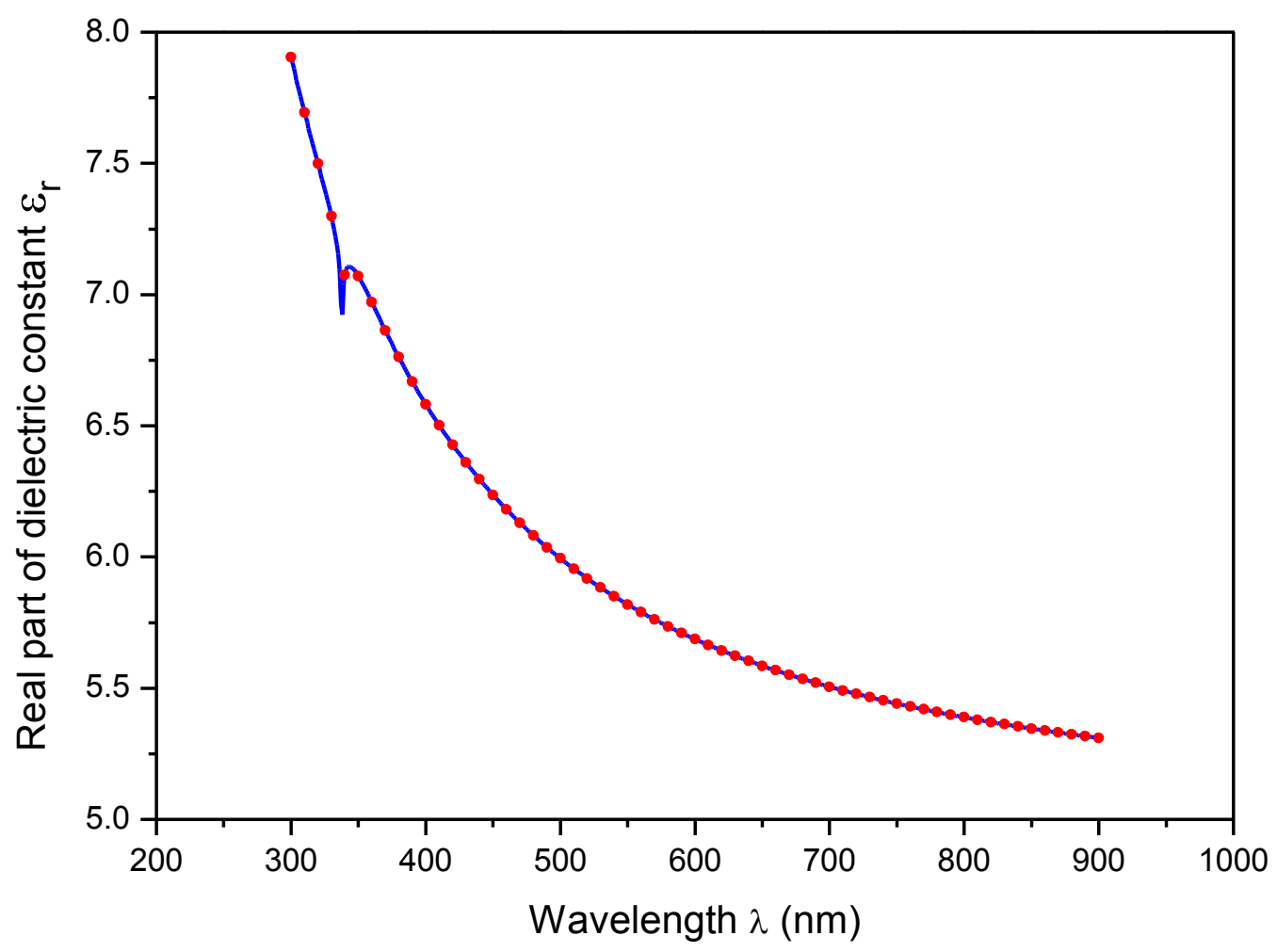

Fig. 6. The variation of real part of of the dielectric constant of $\mathrm{ZnS}$ thin film on wavelength.

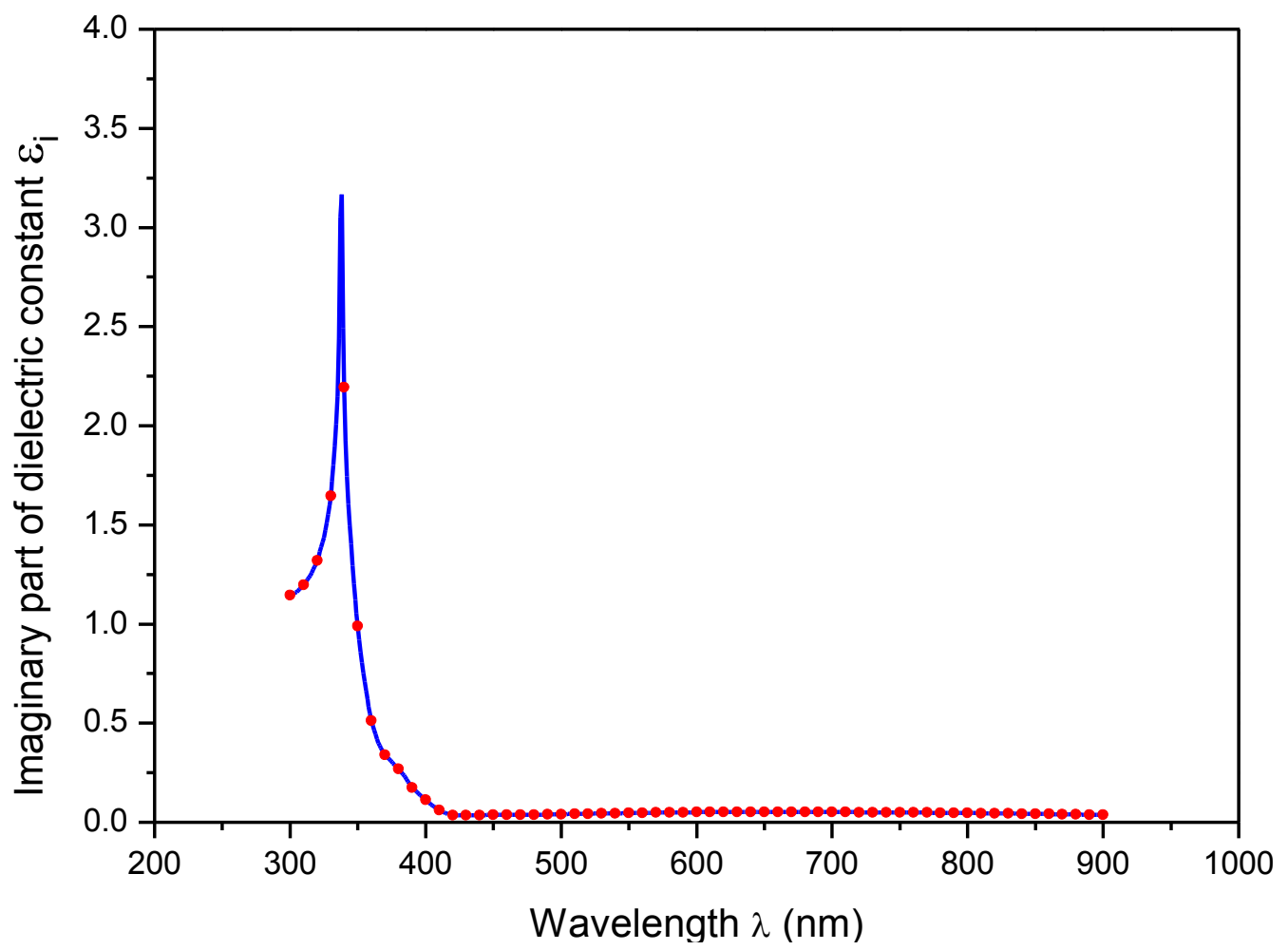

Fig. 7. The variation of imaginary part of the dielectric constant of $\mathrm{ZnS}$ thin film on wavelength. 


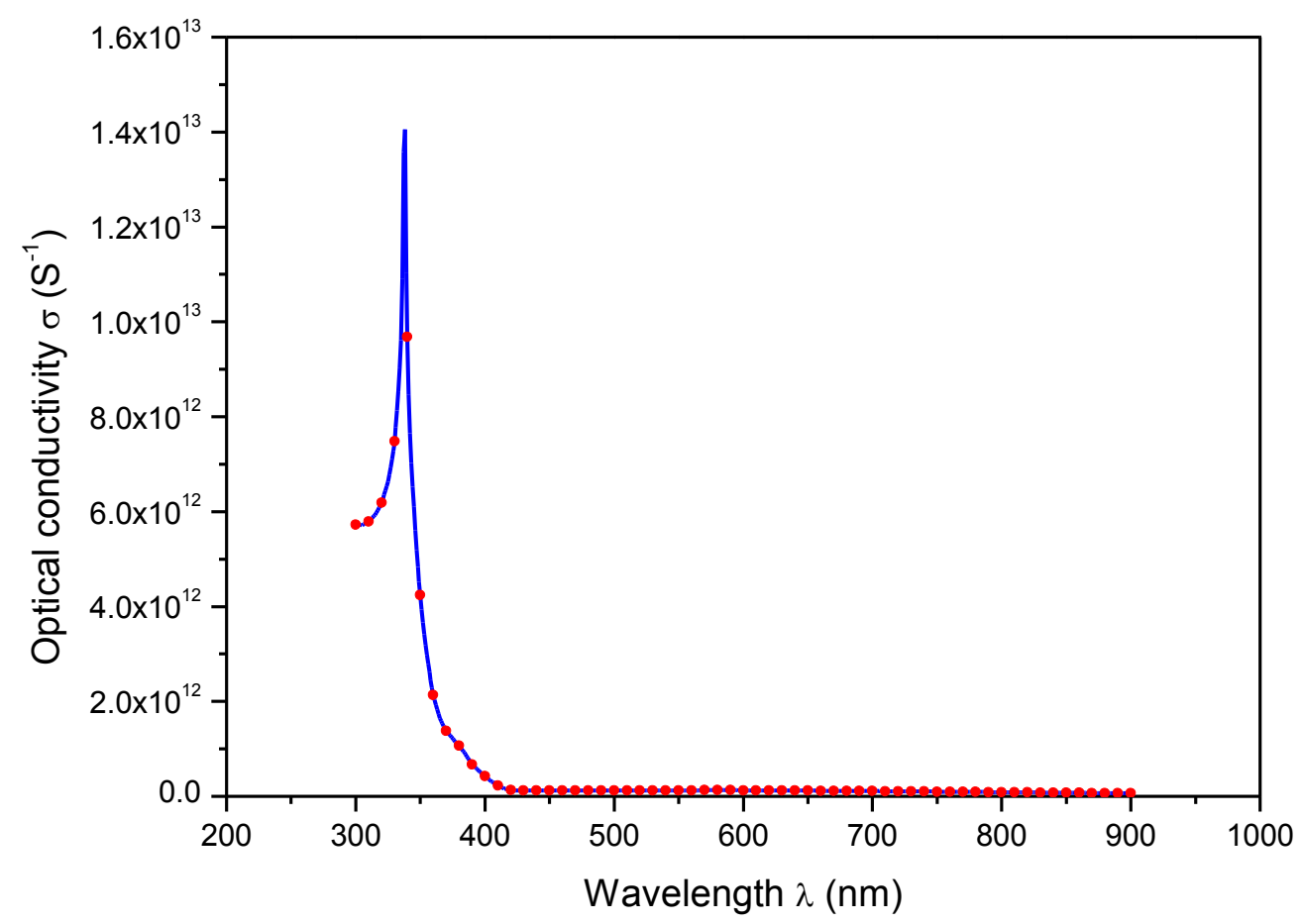

Fig. 8. The dependence of the optical conductivity on wavelength.

\section{CONCLUSIONS}

In summary, $\mathrm{ZnS}$ thin films were prepared successfully by flash evaporation technique. The refractive index and the thickness were obtained from the transmission data by using Swanepoel method. It was found that the calculated value of the thickness, which obtained by using the envelope method was in a good agreement with the thickness value which measured by gravimetric method and the difference was $\sim 4 \%$. The results also showed that the static refractive index value which obtained from the dispersion relation was in a good agreement with the value which calculated from Cauchy's relation. The optical energy gap was found to be equal to $3.61 \mathrm{eV}$.

\section{References}

[1] X. Wu, F. Lai, L. L. Jing Lv, B. Zhuang, Q. Yan, Z. Huang, Appl. Surf. Sci. 254 (2008) 6455.

[2] A. Oliva, I.González-Chan, V. Rejón, J. Rojas, R. Patiño, D. Aguilar, CCE, IEEE, (2010) 500-503.

[3] P. O'Brien, D. J. Otway, D. Smyth-Boyle, Thin solid Films 361 (2000) 17.

[4] Tokio Nakada, Masashi Hongo, Eiji Hayashi, Thin Solid Films 431-432 (2003) 242-248.

[5] M.A. Contreras, T. Nakada, M. Hongo, A.O. Pudov, J.R. Sites, Proceedings 3rd World Conference of Photovoltaic Energy Conversion,Osaka, Japan, (2003) 570. 
[6] S. Yamaga, A. Yoshokawa, H. Kasain, J. Cryst. Growth 86 (1998) 252.

[7] J . Cheng, D.B. Fan, H. Wang1, B.W. Liu, Y. C. Zhang, H. Yan, Semicond. Sci. Technol. 18 (2003) 676.

[8] P. J.Borah, C. K.Sarma, Acta Phys. Pol. A 114 (2008) 713.

[9] D. Kurbatov, S. Kshnyakina, A. Opanasyuk, V. Melnik, V. Nesprava, Rom. J. Phys. 55 (2010) 213.

[10] R. K. Murali, S. Vasantha, K. Rajamma, Mater. Lett. 2 (12-13) (2008) 1823.

[11] X. Wu, F. Lai, L. Lin, J. Lv, B. Zhuang, Q. Yan, Z. Huang, Appl. Surf. Sci. 254 (2008) 6455-6460.

[12] A. Ateş, M. Ali Yıldırım, M. Kundakc1, A. Astam, Mater. Sci. Semicond. Process. 10 (2007) 281.

[13] P. K. Ghosh, S. Jana, S. Nandy, K. K. Chattopadhyay, Mater. Res. Bull. 42 (2007) 505.

[14] T. Kryshtab, V.S. Khomchenko, J.A. Andraca-Adame, L.V. Zavyalova, N.N. Roshchina, V.E. Rodionov, V.B. Khachatryan, Thin Solid Films 515(2) (2006) 513-516.

[15] B. A. Bhalerao, D. C. Lokhande, G. B.Wagh, IEEE. Trans. Nanotechnol. 12(6) (2013) 996-1001.

[16] D. Balamurugan, B.G. Jeyaprakash, R. Chandiramouli, J. Appl. Sci. 12 (2012) 17011705.

[17] N. F. Haubi, K. A. Midhjil, H. G. Rashid, H. L, Mansour, Mod. Phys. Let. B 24 (2010) 28.

[18] R. Swanepoel, J. Phys. E: Sci. Instrum. 17 (1984) 896.

[19] Nabeel Ali Bakr, PhD. Thesis Pune university India (2010).

[20] R. Swanepoel, J. Phys. E: Sci. Instrum. 16 (1983) 1214.

[21] T. S. Moss, Optical properties of semiconductors (Butterworths, London, 1959).

[22] S. H. Wemple, M. DiDomenico, Phys. Rev. Lett. 23 (1969) 1156.

[23] S. H. Wemple, M. DiDomenico, Phys. Rev. B 3 (1971) 1338.

[24] J. L. Pankove, " Optical processes on semiconductors Dover publication", New York 1967.

[25] N. A. Bakr, A. M. Fund, V S Waman, M. M. Kamble, R. R Hawaldar, D. P. Amalnerkar, S. W. Gosavi, Pramana - J. Phys. 76(3) (2011) 519-531.

[26] J. Tauc, The optical properties of solids (North-Holland, Amsterdam, 1970).

[27] P. Roy, J.R. Ota, S.K. Srivastava, Thin Solid Films 515 (2006) 1912.

[28] K. Takeuchi, M. Ichimura, E. Arai, Y. Yamazaki, Sol. Energy Mater. Sol. Cells 75 (2003) 427.

[29] J. M. Doña, J. Herrero, J. Electrochem. Soc. 141 (1994) 205.

[30] J. C. Manifacier, J. Gasiot, J. P. Fillard, J. Phys. E 9 (1976) 1002.

[31] E.R. Shaaban, J. Phys. Chem. 73 (2012) 1131. 
[32] Raid A. Ismail, Nadir F. Habubi, Hussam R. Abid, International Letters of Chemistry, Physics and Astronomy 4 (2014) 37-47.

[33] Ali M. Mous, Selma M. Al-Jawad, Suad M. Kadhim Al-Shammari, International Letters of Chemistry, Physics and Astronomy 6 (2014) 16-25.

[34] Hanan R. A. Ali, International Letters of Chemistry, Physics and Astronomy 8 (2014) 47-55.

[35] Raghad Y. Mohammed, S. Abduol, Ali M. Mousa, International Letters of Chemistry, Physics and Astronomy 11(2) (2014) 146-158.

[36] S. M. Patil, P. H. Pawar, International Letters of Chemistry, Physics and Astronomy 17(1) (2014) 21-36.

[37] S. M. Patil, P. H. Pawar, International Letters of Chemistry, Physics and Astronomy 17(2) (2014) 153-167. 